\title{
HONG KONG 2018
}

Miriam Laura Sánchez César

City University of Hong Kong

\section{INTRODUCCIÓN}

Desde que Hong Kong pasó a dominio colonial británico como resultado del Tratado de Nanjing de 1842, la brecha entre China continental y la isla se hizo muy amplia, política y económicamente. En primer lugar, gran parte de la población de Hong Kong estaba constituida por chinos que huían de los conflictos en continente (Segunda Guerra Mundial y Guerra Civil China) y de la inestabilidad política y económica de las primeras décadas del régimen maoísta. En segundo lugar, aunque el gobierno colonial de Hong Kong no fue de ninguna manera democrático, garantizaba un respetable nivel de libertades civiles y de derechos humanos; no se puede decir lo mismo del sistema político en China (Wong, 2017). Además, Hong Kong ha practicado una economía de mercado con un alto nivel de internacionalización comparable con el de otros países desarrollados en términos de PIB per cápita. Todas estas diferencias han contribuido a la "crisis de confianza" surgida durante el periodo de transición que se intensificó después de 1989.

Dadas las anteriores circunstancias, la República Popular China (RPC) adoptó un enfoque pragmático sobre el futuro de la isla. De acuerdo con la Declaración Conjunta sinobritánica de 1984, Hong Kong es gobernado por la RPC bajo el principio conocido como "un país, dos sistemas" (Wong, 2017). El acuerdo garantiza que la isla funcionará como una Región Administrativa Especial (RAE) de China hasta 2047; es decir, la ciudad mantiene un sistema judicial separado, sistema educativo diferente; ejerce las libertades políticas y civiles vigentes antes de que el Reino Unido retornara su soberanía a China en 1997. Sin embargo, la dificultad de reconciliar puntos de vista divergentes sobre esta premisa continúa siendo un 
reto para Hong Kong. Mientras Beijing ha tratado de ejercer una mayor influencia sobre los asuntos de la isla, ésta sigue siendo mucho más libre que China continental, donde las elecciones abiertas son prácticamente inexistentes. Equilibrar las demandas de control político de Beijing y la necesidad de mantener cierto grado de libertad política en Hong Kong representan un gran desafío año con año, pero el futuro de la ciudad depende de ello.

La importancia global de Hong Kong es mayor de lo que muchas personas, especialmente en el mismo Hong Kong, suponen. Lo que hace a la isla un lugar especial es su papel único en China, combinado con su estado de derecho, educación de clase mundial, medios de comunicación desarrollados, y su población. Éstas, sin duda, son las bases de la fortaleza de Hong Kong y su valor para China. No obstante, al mismo tiempo también provoca que en determinadas circunstancias la ciudad sea increíblemente incómoda para Beijing. Si los nuevos líderes de Hong Kong son capaces de resolver las tensiones entre Beijing y los locales, la ciudad podría tener un futuro promisorio; pero si el malestar político continúa creciendo durante el presente periodo de gobierno, la ciudad podría tener dificultades para seguir desarrollándose.

\section{SITUACIÓN POLÍTICA}

Los hongkoneses votaron el 11 de marzo de 2018 para elegir a seis nuevos legisladores. La contienda incluía asientos en la isla de Hong Kong, al oeste de Kowloon y al este de Nuevos Territorios, así como un lugar para representar a los sectores de Arquitectura, Topografía, Planificación y Paisaje. La elección se llevó a cabo para ocupar cuatro escaños en el Consejo Legislativo que quedaron vacantes después de que seis legisladores pro-democracia fueran destituidos por no haber jurado sinceramente lealtad a Beijing. El resultado de la elección fue que los activistas a favor de la democracia sufrieron un duro golpe, ya que no lograron recapturar dos de los cuatro escaños que les permitirían ejercer influencia crítica en el gobierno de la ciudad (Bland, 2018).

En 2018 la participación ciudadana en las elecciones fue de 43\%, comparado con el $58 \%$ de los votantes que ejercieron su derecho al sufragio a finales de 2016. David Zweig (2017), profesor de ciencia política en la Universidad de Ciencia y Tecnología de Hong Kong, dijo que el "creciente autoritarismo" de Beijing parece estar generando un sentimiento más amplio de desilusión hacia el movimiento prodemocrático. Además, la falta de liderazgo, 
ideas claras y objetivos comunes ha llevado a muchas personas que respaldaron el Movimiento de Ocupación en 2014, a darle la espalda. Actualmente los partidos prodemocracia tienen 26 escaños en una legislatura compuesta por 70 miembros, y aproximadamente la mitad de los legisladores tiene vínculos con empresas y grupos comerciales que son abrumadoramente pro-Beijing (Haas, 2018a).

Las elecciones se celebraron el mismo día que se anunciaron los cambios constitucionales que entronizaran a Xi Jinping en el poder de la RPC de manera indefinida. La decisión de centralizar el poder y de aumentar sus funciones políticas, económicas y de otro tipo supone una ruptura con la tradición establecida en 1982 del liderazgo colectivo (Ríos, 2018). La confirmación del Comité Central del Partido Comunista y de la Asamblea Popular Nacional respecto a la anulación del límite constitucional de dos mandatos posiblemente aumentará la sensación de frustración en Hong Kong, ya que es factible que intensifique la represión contra la oposición en la antigua colonia británica. Es evidente que durante los últimos años Beijing ha tomado una postura cada vez más dura contra la disidencia en Hong Kong, y las elecciones de 2018 han sido vistas como una muestra de la creciente influencia del Partido Comunista Chino (PCC) en la isla (Haas, 2018a). No obstante, el enfoque de mano dura de la RPC en Hong Kong no es una tendencia aislada, más bien es el resultado de una China más segura y confiada en instancias internacionales. Una RPC más fuerte siempre ha implicado un enfoque menos flexible en asuntos que considera cruciales; China es ahora más fuerte que en el pasado, y dicha posición le permite subir la apuesta por Hong Kong. En este sentido, la cuestión territorial es un tema central que se halla atado al simbolismo de la humillación colonial para China.

El creciente sentido del nacionalismo chino ha llevado inexorablemente a una gradual alienación y sentimientos antipopulares en Hong Kong. La narrativa de la RPC como elemento representativo del rejuvenecimiento nacional chino contrasta con el desarrollo en Hong Kong de una identidad separada. La narrativa de reunificación es parte integral del discurso de Xi Jinping, misma que también se extiende a la audiencia en continente y es recibida con entusiasmo (Englund, 2018). No obstante, dicha postura ha llevado a que Beijing no comprenda que la resistencia en Hong Kong va más allá de sólo tomar parte en las oportunidades del crecimiento económico ofrecidas por China. Hong Kong desarrolló una identidad y un estilo de vida muy diferentes a los de China continental, mismos que la mayor parte de la población no está dispuesta a negociar. 
Sin embargo, cualquier disidencia contra el gobierno en Beijing probablemente se encontrará con una creciente intolerancia del PCC. Es previsible que un futuro cercano Hong Kong mantenga un clima político significativamente más abierto que en continente, pero cualquier acto que desafíe la autoridad y soberanía del gobierno de la RPC impulsará al gobierno central a seguir imponiendo políticas más rígidas hacia la región autónoma. De hecho, la cantidad de publicaciones críticas hacia Beijing ya ha comenzado a disminuir, y se puede prever que estos materiales serán cada vez más restringidos (Englund, 2018). La desaparición de cinco librerías en 2015 fue la señal más preocupante de cómo la mano invisible de Beijing está violando la Ley Fundamental en Hong Kong. En los últimos años, la industria editorial y diversos medios de comunicación han experimentado una severa convulsión debido a la compra de los principales periódicos en Hong Kong por parte de empresarios pro-Beijing. Cuando el gigante chino de internet Alibaba compró el South China Morning Post a finales de 2015, los residentes de Hong Kong se dieron cuenta de que tendrían que luchar para preservar la libertad de prensa a la que están acostumbrados. Sin duda, estos sucesos profundizan el sentimiento de que intereses políticos y económicos han fomentado la censura y que la libertad de prensa en la ciudad está seriamente deteriorada (Davis, 2018). Aunque la violencia contra los periodistas casi se ha detenido, cada vez resulta más difícil cubrir temas que involucran la gobernanza, tanto en Hong Kong como en la China continental.

Beijing ha evocado poderes para reescribir las leyes de Hong Kong, tomándose medidas especialmente para criminalizar cualquier forma de protesta. Por ejemplo, a pesar de las súplicas de la Asociación de Futbol y de las advertencias de que podría haber repercusiones, desde 2016 los aficionados a este deporte en la isla han abucheado o se han negado a asistir a cada juego internacional en casa mientras se toque el himno nacional chino. Ante tal escenario, se está redactando una versión local de la ley de China continental que castiga severamente a cualquiera que no respete el himno nacional, acercando las leyes de la ciudad a las continentales (Lum, 2018a). El 4 de noviembre de 2017, el Comité Permanente del Congreso Nacional del Pueblo adoptó la decisión de agregar la Ley del Himno Nacional al anexo III de la Ley Fundamental de Hong Kong. El proyecto de ley local dice que cualquier persona que distorsione o no respete la "Marcha de los Voluntarios" recibirá una multa de hasta HK $\$ 50000$ y enfrentará una pena de prisión hasta de tres años. 
El gobierno de Hong Kong designado por Beijing también ha buscado encarcelar a decenas de manifestantes y de bloquear políticamente a varios personajes prominentes. En 2016, los tres líderes estudiantiles que encabezaron las protestas prodemocráticas de 79 días en 2014, Nathan Law, Joshua Wong y Alex Chow, fueron juzgados y sentenciados a servicio comunitario por atacar edificios gubernamentales e incitar a otros a participar en reuniones ilegales. Ellos completaron sus sentencias sin privación de libertad en julio de 2017, pero el gobierno pidió un castigo más severo. El 27 de agosto de 2017 volvieron a la corte; los tres recibieron sentencias de prisión, y Joshua Wong, enviado a máxima seguridad. Los tres jóvenes son conocidos como los primeros prisioneros políticos de Hong Kong. El fallo fue ampliamente condenado y la independencia del poder judicial de la ciudad fue puesta en duda (Haas, 2018).

En 2018, a la prominente activista estudiantil Agnes Chow se le prohibió presentarse a elecciones como candidata de su partido debido a sus ideales políticos. Dicha medida penalizó la sola afiliación con una idea política que fue diseñada para que los miembros del partido Demosisto no ingresaron al Consejo Legislativo. Éste fue uno de los golpes más fuertes para los activistas de la democracia en la antigua colonia británica después de un año en el que se vetó a legisladores electos y se encarceló a los líderes de las protestas (Haas, 2018). En el caso de Chow, fue el apoyo de su partido a la idea de "autodeterminación" lo que sepultó su candidatura. Ella forma parte de un grupo con nuevas ideas que busca una orientación diferente para la oposición que desde hace casi dos décadas ha sido dominado por políticos que crecieron bajo el dominio colonial británico que terminó en 1997.

En un movimiento sin precedentes, Hong Kong vetó a un partido político que estaba a favor de la independencia, lo que causó protestas entre los críticos, quienes consideran que esta medida es otra señal del endurecimiento del control de China sobre la ciudad (Kuo, 2018). El 24 de septiembre de 2018, la Oficina de Seguridad de Hong Kong anunció la prohibición del Partido Nacional de Hong Kong (PNHK), un conocido pero no tan numeroso grupo que promueve la idea de independencia de la isla. El partido fue fundado por Andy Chan dos años atrás, y desde su inicio se autoproclamó el primer partido pro-independencia de la ciudad. En marzo de 2016 intentó de postularse para las elecciones legislativas ese mismo año, pero fue descalificado porque se negó a declarar que Hong Kong era una parte inalienable de China. Es la primera vez desde que Hong Kong retornó a soberanía china, que un partido político ha sido prohibido. A partir de julio del presente año la policía recomendó 
la prohibición del PNHK en virtud de la Ordenanza de Sociedades, la cual estipula que los grupos políticos pueden ser declarados ilegales cuando representen un peligro para la seguridad de la isla, aunque nunca hayan empleado la fuerza (Ramzy, 2018). El gobierno dijo también que el partido promovió un discurso de odio y discriminación contra los chinos del continente, describiéndolos como partidarios de Beijing que quitaban recursos a los hongkoneses. Además, se argumentó la prohibición del partido con base en la flagrante violación de la Ley Fundamental, cuyo primer artículo establece que la ciudad es una parte inalienable del territorio chino.

Existe preocupación por que esta acción establezca un precedente sobre cómo será invocada la Ordenanza de Sociedades y la Ley Fundamental de aquí en adelante. Especialmente se teme que "cuestiones de seguridad nacional" sean usadas para prohibir o limitar a las personas que respalden la independencia de Hong Kong. El castigo por unirse, asistir o contribuir con organizaciones que han sido prohibidas es una multa de HK \$20 000 y encarcelamiento por un año, aunque reincidentes pueden permanecer dos años en prisión. La Oficina de Educación de Hong Kong advirtió a secundarias y universidades que se aseguren que sus estudiantes no se asocien al PNHK, ya que esto podría constituir una ofensa criminal (Cheung and Su, 2018). El gobierno chino está decidido a defender su soberanía a cualquier precio, y no tolerará ningún elemento de inestabilidad que atente contra esta tarea.

En el último informe semestral al Parlamento británico sobre Hong Kong, el secretario de Relaciones Exteriores del Reino Unido, Jeremy Hunt, observó que "la mayoría de las disposiciones" de la Declaración Conjunta sino-británica de 1984 se estaban implementando fielmente, y que el principio "Un país, dos sistemas" continuaba funcionando bien. Sin embargo, expresó su preocupación por la continua presión sobre la autonomía de Hong Kong y los derechos y libertades garantizados por la Declaración Conjunta y consagrados en la Ley Fundamental. El gobierno del Reino Unido ha señalado que la opción sobre la independencia no es realista ni deseable para Hong Kong; sin embargo, aseveró que el derecho de libertad de expresión está garantizado por la Declaración Conjunta y consagrado en la Ley Fundamental. El informe de 20 páginas menciona incidentes entre enero y junio, incluidos el de los tres individuos a los que se les prohibió postularse para las elecciones legislativas de marzo en función de sus convicciones políticas, el enjuiciamiento de legisladores y de manifestantes prodemocráticos, y la controversia sobre la base legal para el acuerdo del punto de control conjunto en la terminal ferroviaria de alta velocidad (Cheng, 2018). En respuesta 
al informe, la Oficina del Comisionado del Ministerio de Relaciones Exteriores en RPC dijo que la independencia de Hong Kong viola la Constitución china, la Ley Fundamental y las leyes pertinentes de Hong Kong, perjudica la seguridad, la soberanía e integridad territorial de la nación, y no está dentro del alcance de la libertad de expresión.

El 1 de julio 2018 no sólo se cumplieron 21 años del regreso de Hong Kong a China, sino también del primer año en el cargo de la señora Carrie Lam como titular del ejecutivo de Hong Kong, tiempo durante el cual se ha esforzado por estrechar vínculos con el gobierno central chino. El ex titular, C.Y. Leung, anunció que no estaba interesado en buscar otro mandato, en alusión a compromisos familiares. Sin embargo, se especuló que Beijing había perdido la esperanza de liderar exitosamente a Hong Kong, o bien de recibir suficientes votos. Los candidatos a jefe del Ejecutivo en 2017 estuvieron en competencia sobre quién era capaz de conciliar mejor intereses ampliamente divergentes, además de obtener el visto bueno por parte de Beijing. Wang Guangya, director de la Oficina de Asuntos de Hong Kong y Macao del Consejo de Estado de Chino, señaló que además de amar a China y a Hong Kong, competencias administrativas excepcionales, y de contar con el apoyo de la gente de la isla, la confianza del gobierno central es ahora un requisito explícito (Cheung, 2018). La ex secretaria en jefe de la Administración Carrie Lam derrotó al ex secretario de Finanzas John Tsang y al juez retirado Woo Kwok-Hing, con 777 votos del Comité Electoral, de 1194 miembros.

La señora Carrie Lam ha trabajado en el servicio civil de carrera la mayor parte de su vida, después de unirse como oficial administrativo al Departamento de Vivienda en 1980. Ella tuvo varios ascensos antes de mudarse al Reino Unido en 2004, para encabezar la Oficina de Comercio de Hong Kong en Londres. En 2012 consiguió convertirse en la número dos en la escala de poder en Hong Kong. Actualmente, Lam se encuentra en medio de un cada vez más autoritario mandato del presidente Xi Jinping y de una población que en su mayoría se encuentra ferozmente opuesta a la erosión de derechos humanos y aspiraciones democráticas por parte de Beijing (Huang, 2018). En el sistema híbrido hongkonés, el jefe del Ejecutivo es aprobado por el PCC, pero está obligado a mantener las libertades civiles, dejando a Lam sin la legitimidad de un mandato demográfico, y la autoridad sin restricciones de un líder en China continental. La postura de Lam respecto a las relaciones entre China y Hong Kong fue confirmada por el presidente chino, Xi Jinping, quien pronunció un discurso en la ceremonia para conmemorar el vigésimo aniversario del regreso de Hong Kong a China. Xi enfatizó que 
"cualquier intento de poner en peligro la soberanía nacional y la seguridad, desafiar el poder del gobierno central y la autoridad de la Ley Fundamental de la RAE de Hong Kong o usar la isla para llevar a cabo actividades de infiltración y sabotaje contra el territorio chino, es un acto que cruza la línea roja, y es absolutamente inadmisible" (SCMP Staff, 2017). Además, el presidente prometió seguir apoyando a Hong Kong para que desempeñe un papel clave en proyectos iniciados por el gobierno central. Dichos planes son cruciales para profundizar la integración entre China y Hong Kong. Durante el primer año de la administración de Carrie Lam, sin duda dicha tarea ha sido una prioridad.

\section{ECONOMÍA Y EL EFECTO DE LA GUERRA COMERCIAL ENTRE ESTADOS UNIDOS Y CHINA EN LA ISLA}

Aunque Hong Kong enfrenta importantes retos en materia política, éstos no son los únicos. Reorientar la economía al servicio de residentes locales en lugar de turistas de continente o de la élite de negocios es sin duda uno de los reclamos más enérgicos de la sociedad hongkonesa. Como la décima potencia comercial más grande y el tercer centro financiero más grande del mundo, a menudo se cita a Hong Kong como un modelo de economía de libre mercado. Su estructura económica estuvo expuesta durante la crisis financiera internacional, pero finalmente resistió bien. El PIB real de Hong Kong aumentó 3.8\% interanual en 2017, y se prevé que su economía crecerá de 3 a $4 \%$ en 2018. Hong Kong continúa teniendo finanzas públicas sólidas, con una deuda pública casi inexistente, un fuerte superávit en cuenta corriente y un importante superávit presupuestario. Los servicios financieros, el comercio y la logística, el turismo y los servicios profesionales y de productores, son las cuatro industrias clave en Hong Kong. Han sido la fuerza motriz del crecimiento económico, han impulsado el crecimiento de otros sectores económicos y han creado empleos (GovHK, 2018).

Hong Kong ha cosechado la mayor parte de los beneficios del crecimiento económico del continente, donde el sector financiero es el más productivo y al mismo tiempo altamente dependiente de condiciones externas. Gran parte del sector financiero hongkonés depende del comercio, la inversión y las transacciones con China y con el resto del mundo. La isla ha estado en el centro del cambio de la economía global en la dirección de China. Banqueros y ejecutivos expatriados han acudido a la ciudad y creado un ambiente innovador previamente experimentado, principalmente en Nueva York y Londres, ofreciendo transparencia, estado 
de derecho y servicios bancarios de primer mundo, comparado con la opacidad del sistema chino.

Dicho estatus se encuentra en peligro debido a la progresiva guerra comercial entre Donald Trump y Xi Jinping. Uno de los temas más comentados durante este 2018 ha sido cómo se han involucrado Estados Unidos y China en una guerra comercial. En agosto de 2018, EUA impuso un arancel de $25 \%$ a las importaciones chinas por un valor de $200 \mathrm{mil}$ millones de dólares. Sin embargo, una guerra comercial en el contexto de una economía globalizada deja víctimas colaterales más allá de las potencias implicadas. Técnicamente, la isla se encuentra blindada por el Acta Política de los Estados Unidos y Hong Kong, la cual ha tratado a la ciudad al margen de China en términos de comercio, exportación y economía, desde el retorno a la soberanía china en 1997 (Tsang, 2018). Por lo tanto, los aranceles que EUA impuso a China no se aplican a Hong Kong.

Al menos en papel, Hong Kong está un poco alejado de los 50 mil millones de dólares por impuestos sobre bienes chinos que Washington implementó, pero como intermediario clave de la interacción de China con la economía mundial, también sufrirá consecuencias (Bryan, 2018). Con base en una lista de productos chinos por valor de 34000 millones de dólares, el gobierno de Hong Kong dijo que alrededor de 17\% (7.6 mil millones) de las exportaciones chinas en cuestión pasaron por la ciudad hacia EUA. El 9\% de las exportaciones procedentes de EUA pasaron vía Hong Kong hacia la China continental. De acuerdo con fuentes oficiales del gobierno, en Hong Kong los comerciantes de la ciudad serían los primeros en cargar con los efectos de la guerra comercial y la última ronda de aranceles impuestos por Estados Unidos a bienes chinos por un monto de 200 mil millones de dólares. Dichas tarifas de 25\% aumentarán el costo en los negocios, y en última instancia serán asumidos por los consumidores.

Hong Kong, en cierto sentido, es una víctima de su éxito. Llegó a avasallar al universo más amplio de los mercados emergentes, particularmente en acciones. Además, los vínculos cada vez más profundos de Hong Kong con el rápido crecimiento económico de China y su vinculación con el dólar le dieron una ventaja sobre Singapur, Tokio y otros aspirantes a centros financieros asiáticos. 


\section{HoNG KONG EN LA INICIATIVA DEL ÁREA DE LA GRAN BAHÍA CHINA}

El Área de la Gran Bahía se refiere al esquema del gobierno chino para unir las ciudades de Hong Kong, Macao, Guangzhou, Shenzhen, Zhuhai, Foshan, Zhongshan, Dongguan, Huizhou, Jiangmen y Zhaoqing en un centro económico y comercial, con una población total de más de 66 millones y un PIB anual de más de 1.5 billones de dólares. Este proyecto se presentó en el 13o. Plan Quinquenal de China (2016-2020), y el año pasado se incluyó en el informe de trabajo del gobierno chino. El 1 de julio de 2017, importantes funcionarios de estas ciudades, incluida la señora Carrie Lam, firmaron un acuerdo marco que oficializó el comienzo del proyecto. Una de las principales apuestas de la presente administración hongkonesa ha sido contribuir al desarrollo de esta iniciativa, afirmando que el futuro de la ciudad dependerá de manera importante en su capacidad para innovar y conectarse con el mundo. Sin duda la inclusión de Hong Kong en el proyecto es clave, ya que su sistema de libre mercado y su marco jurídico proporcionan un entorno empresarial a la altura de estándares internacionales, además de que facilitan el camino a las compañías chinas en su meta por expandirse globalmente.

En este contexto, la infraestructura es indispensable para el éxito de dicha iniciativa. La sección de Hong Kong del enlace ferroviario de lo que será el expreso GuangzhouShenzhen-Hong Kong (XRL) se inauguró el 23 septiembre de 2018. Su propósito es enlazar a Hong Kong con la red ferroviaria china de alta velocidad en las 16 principales ciudades de China continental, lo que reduciría significativamente el tiempo de los trayectos. La sección de Hong Kong del enlace ferroviario exprés se extiende desde la estación del oeste de Kowloon hacia el norte, hasta el límite con Shenzhen, donde se conecta con la sección continental. El proyecto reforzará el papel de Hong Kong como puerta de entrada al sur de China. Además, fomentará vínculos económicos más estrechos entre ambas partes, lo que inyectará impulso y creará nuevas oportunidades para el desarrollo a mediano y largo plazos (Haas, 2018b). El gobierno de Hong Kong financió el costo del proyecto hasta por HK $\$ 84420$ millones, mientras que la iniciativa privada asumió los costos por encima de esta cantidad.

Desde que comenzó la construcción del tramo de $26 \mathrm{~km}$ en 2010, el proyecto ha generado tensiones entre las partes involucradas. Por ejemplo, ha habido daños físicos en los edificios adyacentes, se generaron importantes niveles de contaminación por los trabajos de 
construcción y la eliminación de asentamientos y comunidades locales, además de los gastos excesivos y de las demoras en el mismo. No obstante, la crítica central ha girado en torno al proyecto de co-ubicación. La zona portuaria continental designada, que se ubica en la estación ferroviaria del oeste de Kowloon, mide alrededor de un millón de pies cuadrados y es controlada por la policía y funcionarios de aduanas chinos. El secretario de transporte de la ciudad y un importante funcionario del partido comunista de la provincia de Guangdong realizaron conjuntamente una ceremonia para marcar el inicio de actividades del área. El evento fue a puerta cerrada, y ni los medios de comunicación ni los legisladores locales recibieron notificación previa.

Desde que el gobierno de Hong Kong dio a conocer la propuesta en julio de 2017, su base legal no ha sido clara, auque sí ha sido objeto de acalorados debates entre funcionarios, expertos legales y legisladores. Se argumenta que la co-ubicación de instalaciones para control de entradas y salidas permitirá a los pasajeros someterse a inspecciones por parte de las autoridades de China continental y de Hong Kong en el mismo lugar (Cheung, 2017). El 15 de junio de 2018, el Consejo Legislativo de Hong Kong aprobó el proyecto de coubicación del enlace ferroviario Guangzhou-Shenzhen-Hong Kong después de varios meses de deliberación, con lo que se concluyó el último paso hacia el objetivo final: comenzar las operaciones de la sección XRL de Hong Kong en septiembre de este año. Se requirió la aprobación del comité permanente, ya que con la propuesta de "co-ubicación" del punto de control los oficiales de China continental recibirían jurisdicción casi total sobre una sección de la terminal del oeste de Kowloon. Dicho movimiento permitirá que los documentos de los viajeros sean revisados por los oficiales de Hong Kong y la parte continental, en lugar de revisarlos por separado antes o después de entrar a la isla.

Desde la perspectiva de muchas voces en Hong Kong, esta solución ha violado el principio de "un país, dos sistemas" y ha erosionado aún más el grado de autonomía que la antigua colonia británica podía disfrutar según su Ley Fundamental. El artículo 18 de ésta señala que la jurisdicción china no se aplicará en Hong Kong, salvo las enumeradas explícitamente en un anexo, y después de un proceso legislativo local. Los principales escépticos temen que el acuerdo de co-ubicación pueda establecer un precedente para aplicar mecanismos similares en otros espacios. Temen también que pueda conducir a medidas para limitar la supervisión constitucional de los tribunales de Hong Kong, como parte del plan de Beijing para ejercer poderes generales de gobierno sobre la Región Administrativa Especial. 
Es muy pronto para saber el impacto real del acuerdo de co-ubicación. Entre los grupos hongkoneses moderados existe un apoyo considerable debido a los potenciales beneficios económicos que existen. Además, consideran que el temor a una mayor influencia china en la isla se encuentra sobredimensionado, argumentando que Hong Kong requiere un enfoque diferente para abordar sus políticas. Es importante contextualizar esta controversia en el ánimo cada vez más pesimista sobre el futuro político de Hong Kong. El acuerdo de coubicación es interpretado por muchos como otro incidente de intrusión continental; la desconfianza mutua entre ambas partes ha reforzado los comportamientos negativos y creado una gran espiral entre Beijing y Hong Kong.

El delta del río Perla ha sido visto como una región pionera en la Política de Reforma y Apertura de China y como un centro económico de gran importancia. Desde el inicio de la reforma económica china se han logrado avances significativos en el desarrollo del transporte desde Hong Kong y Macao hasta China continental. No obstante, aún eran insuficientes para satisfacer las necesidades de transporte regional. Además del proyecto de infraestructura antes mencionado se encuentra el puente Hong Kong-Zhuhai-Macao (HZM), de 55 kilómetros de longitud; de travesía, el más largo del mundo. Aunque su construcción comenzó en 2009 y empezará operaciones a finales de 2018, la idea de edificar un puente que conecte Hong Kong con Zhuhai y Macao ha existido por décadas. Para la construcción del Puente HZM la contribución total fue de RMB ¥15.73 mil millones, de los cuales el gobierno de Hong Kong contribuyó con RMB $¥ 6.75$ mil millones (HZM, 2018). El Puente HZM consta de tres partes principales: el puente y el túnel costa afuera, el cruce de instalaciones fronterizas en Hong Kong, Zhuhai y Macao, y las carreteras de enlace en estos tres puntos. Dicho proyecto de infraestructura es central dentro de la iniciativa de la Gran Área de la Bahía de China, cuyo objetivo es reducir el tiempo en el trayecto entre las tres ciudades, de tres horas a sólo 30 minutos; además de satisfacer la demanda de transporte terrestre de pasajeros y carga entre Hong Kong, China continental y Macao. En resumen, dicho puente es esencial y urgente para coordinar, desarrollar e interconectar plenamente la red continental de autopistas con las de Guangdong, Hong Kong y Macao, mejorar el entorno de inversión, acelerar el ajuste y la optimización del diseño industrial, y mejorar la competitividad integral del río Perla (Asia Times Staff, 2018).

Ahora bien, aunque la idea original del puente era mover más fácilmente los bienes fabricados en Hong Kong, con el declive del sector manufacturero, otras consideraciones 
como promover el turismo regional, acortar el tiempo de viaje y fomentar vínculos más cercanos cobraron mayor relevancia. Se espera que crezca el número de visitantes de Macao, Zhuhai y del delta occidental a Hong Kong. Los enlaces de transporte terrestre entre Hong Kong y ciudades como Foshan, Zhongshan y Jiangmen son innegablemente débiles (Hale, 2018). En este contexto, las compañías de autobuses de Hong Kong se preparan para dar una dura competencia a las empresas de transbordadores marítimos que cruzan el estuario del río Perla tan pronto como el puente inicie operaciones a finales de 2018, ya que sea anunciado que proporcionarán una forma más barata de llegar a estos tres destinos. Sin embargo, la disponibilidad de esta opción de transporte afectará negativamente a la demanda de las compañías de transbordadores marítimos.

A pesar de los enormes beneficios que dicha infraestructura traerá a la Gran Área de la Bahía de China, no ha estado exenta de controversias. En particular, los RMB ¥1.5 mil millones extra que se han tenido que desembolsar, los dos años de retraso en su apertura, la destrucción del hábitat de los delfines blancos, y el intento por parte del personal de una empresa de consultoría, de falsificar los resultados en pruebas de seguridad. Además, si más vehículos continentales con permisos transfronterizos ingresan a territorio hongkonés, las condiciones del camino, particularmente en Lantau y en la parte oeste de los Nuevos Territorios, podrían deteriorarse. Igualmente, si los propietarios en distritos como Tuen Mun y Tung Chung ven un mayor flujo de personas y bienes como resultado del puente, esto podría servir como excusa para elevar los precios de las viviendas y de los alquileres.

Para los más radicales el puente representa una pieza de propaganda infraestructural para anunciar la unidad de China y sus RAE, a pesar de sus diferentes marcos legales y económicos. Los excesos presupuestarios también han sido muy impopulares dado que Hong Kong es una de las sociedades más desiguales del mundo y el gobierno podría usar su riqueza para mejorar los programas de bienestar social, atención médica y educación. Éstos son sólo algunos de los impactos adversos que el gobierno hongkonés debería estar preparado para afrontar después de que se inaugure el puente, a fin de no echar a perder ninguna de sus implícitas oportunidades de desarrollo. Como podemos ver, ambos proyectos están diseñados para mejorar la conectividad y las comunicaciones entre Hong Kong y China continental, a fin de generar oportunidades económicas y sociales para ambas partes. Sin embargo, no han estado libres de la discusión que rodea muchos de los aspectos de las relaciones entre la isla y el continente. 


\section{LA BURBUJA INMOBILIARIA Y LA PROFUNDA DESIGUALDAD SOCIAL QUE EXISTE EN LA ISLA}

A pesar de ser una de las ciudades más ricas del mundo y de contar con un gobierno con más de 100 mil millones de libras esterlinas en reservas fiscales, Hong Kong sigue siendo una sociedad profundamente desigual. Su mercado inmobiliario es el más caro del mundo, lo que hace cada vez más complicado para sus residentes poder adquirir una vivienda. Por ejemplo, un residente promedio necesitaría ahorrar más de 18 años de salario antes de impuestos para poder pagar una vivienda. Alrededor de 200 mil personas viven en pisos subdivididos, según un informe del gobierno de 2017, con más de 65\% de las familias viviendo en unidades de entre 7 y $13 \mathrm{~m}^{2}$. Estas viviendas van desde departamentos construidos ilegalmente en azoteas, hasta habitaciones sin ventanas en lo que una vez fue un departamento de dos habitaciones (Kihara y Chan, 2018). Mientras que las infames "casas ataúdes" de Hong Kong atraen más atención, los departamentos subdivididos son la realidad para muchas más familias.

Hong Kong es el mercado inmobiliario más caro del mundo, un título que ha conservado durante los últimos siete años. Mientras el sector inmobiliario en Hong Kong representa casi $20 \%$ de su producto interno bruto, la capitalización bursátil combinada de las cuatro principales compañías inmobiliarias locales ha aumentado en unos 4520 millones de dólares durante el año pasado. Una combinación de factores estructurales y externos ha contribuido a la elevación de precios en el mercado de vivienda hongkonés. El gobierno de Hong Kong posee todas las tierras de la ciudad y arrienda una cantidad limitada cada año a los desarrolladores para construir viviendas o edificios comerciales. Los desarrolladores le pagan al gobierno una fuerte cantidad por adelantado, conocida como premium, que refleja el valor esperado que pueden obtener del sitio una vez que esté terminado. Por lo tanto, están motivados para establecer precios más altos y obtener mayores ganancias. Al mismo tiempo, el gobierno obtiene $30 \%$ de sus ingresos totales del mercado de bienes raíces, y protege dichos ingresos ajustando el suministro de viviendas. Cada año, desarrolladores de China continental con un amplio poder adquisitivo han entrado a la batalla por conseguir terrenos en Hong Kong. La alta demanda ha provocado que los precios sean mucho más altos que el valor real de la propiedad, y cada día es más difícil ocultar los efectos negativos de dicho mecanismo (Moon, 2018). Por ejemplo, en la isla de Hong Kong las casas medianas tienen un precio de más de HK $\$ 200$ mil por metro cuadrado. Los precios promedio de la vivienda 
son 19 veces el ingreso anual de los residentes locales, mientras que los reembolsos estimados de los préstamos hipotecarios representan el 70\% de los ingresos. La tasa de propiedad de vivienda en Hong Kong saltó sólo 4\% en dos décadas al pasar de 46 a 50\%. Estas cifras están lejos de alcanzar la meta de 70\% marcada por el primer presidente Tung Chee-Hwa en 1997.

Es evidente que el mercado de la vivienda está en una burbuja, ya que los precios se han triplicado en la última década. Además, el alza en los precios de las propiedades y las rentas ha tenido un efecto en cadena que ha elevado los costos de bienes y servicios. Una de las cuestiones más urgentes para la señora Lam es aumentar la protección de las viviendas de alquiler para que la gente con menos ingresos pueda vivir de manera digna. Los segmentos de la población de ingresos medios y bajos son cada vez menos capaces de pagar una vivienda adecuada, por lo que la solución a este problema ha sido una de las prioridades de la presente administración.

La señora Carrie Lam sugirió que 44 mil unidades serían más que suficientes, mientras más de 150 mil familias están en lista de espera para obtener vivienda subsidiada por el gobierno; posteriormente se vio obligada a disculparse por dicha estimación. En este contexto, la señora Lam ha dirigido sus esfuerzos a los jóvenes profesionales locales que luchan por pagar un lugar razonable. Ella planea crear una nueva forma de vivienda subsidiada para compradores con un umbral de ingresos y activos más generoso que el sistema actual. Además, el gobierno planea introducir un impuesto en los inmuebles vacantes en un intento por desalentar a los desarrolladores de acaparar nuevas viviendas. Para justificar la medida, el gobierno señaló que el mercado inmobiliario tiene alrededor de 9 mil nuevos apartamentos vacíos (Tweed, 2018). Mientras tanto, para no dejar de lado a la gente que alquila viviendas, ella también tiene planes para que haya más apartamentos disponibles para arrendamiento en el ajustado mercado inmobiliario.

La vivienda se está convirtiendo en una de las fuentes de estrés más grande para los hongkoneses, quienes firman que su entorno de vida tiene un impacto negativo en su salud mental. La encuesta de una organización no gubernamental reveló que $53 \%$ de las mujeres de entre 20 y 40 años en Hong Kong no quieren tener hijos, y la razón número uno es la aguda escasez de viviendas (Haas, 2017). Además, la comunidad empresarial comienza a quejarse de que la falta de unidades de vivienda debilita la competitividad de la ciudad. Sin 
embargo, aunque la vivienda seguirá siendo uno de los focos críticos, hay muchos otros retos que deberá abordar el nuevo gobierno.

De acuerdo con un estudio publicado por la firma de investigación Wealth-X, Hong Kong superó a Nueva York como el principal destino de millonarios del planeta. La cantidad de personas con un patrimonio neto muy alto (desde 30 millones de dólares) que residen en el centro financiero asiático aumentó casi un tercio en 2017. El incremento en el número de ultra-ricos en Hong Kong fue impulsado por su vibrante mercado de valores y por los crecientes vínculos financieros con la economía china (Shane, 2018). Entre los multimillonarios más destacados de Hong Kong se encuentran Li Ka-Shing, cuyo imperio Cheung Kong controla los puertos, las redes de telecomunicaciones y algunas compañías de energía. El aumento de la riqueza asiática se ha visto favorecido por el aumento en el consumo, más inversión en infraestructura y reformas económicas, entre otros factores.

Sin embargo, la brecha de riqueza en Hong Kong se ha ampliado a un nivel histórico, que sitúa a la ciudad (detrás de Nueva York) como la segunda más desigual del mundo en términos de ingresos, según el informe de distribución de ingresos familiares publicado por el Departamento de Censos y Estadísticas. Por ejemplo, el 10\% más rico de hogares tiene un ingreso mensual promedio de $\mathrm{HK} \$ 112450$, que es 44 veces más que lo que gana el 10\% más pobre, con un promedio de HK \$2 560. Entre las minorías que viven en Hong Kong, los ingresos mensuales medios por hogar en 2016 eran de HK $\$ 32500$, en comparación con el promedio de la ciudad, que es de HK $\$ 25000$. Los hogares blancos fueron los más beneficiados, con alrededor de HK $\$ 60000$, seguidos por coreanos, con HK $\$ 48250$, y japoneses, con $\$ 40000$ pesos hong koneses.

\section{HONG KONG COMO CRISOL CULTURAL Y COMO PUNTO DE TRÁFICO DE PERSONAS}

Gracias a su ubicación e historia única, Hong Kong es un crisol de tradiciones orientales y occidentales. Lo antiguo y lo nuevo se han unido para darle un sello distintivo a la isla. Con el sello de "La ciudad mundial de Asia", Hong Kong es una sociedad formada con personas con múltiples orígenes étnicos. A principios de 2018, un informe publicado por el Departamento de Censos y Estadísticas reportó que, en comparación con una década atrás, 
la cantidad de personas que viven en la ciudad y que no son étnicamente chinos aumentó $70.8 \%$. El gobierno explicó que el aumento se debió principalmente al creciente número de filipinos, indonesios, asiáticos del sur y caucásicos.

Desde la década de 1970, a trabajadoras domésticas extranjeras se les ha permitido permanecer en Hong Kong para solucionar la escasez de mano de obra en labores domésticas. Actualmente hay alrededor de 370 mil trabajadoras domésticas en la isla, de las cuales 54\% vienen de Filipinas, $44 \%$ de Indonesia, y alrededor de 2\% de Tailandia. El salario mínimo para trabajadoras domésticas extranjeras en Hong Kong es dos o tres veces mayor (HK \$4 310) al de Filipinas e Indonesia. Esto sin duda ha ayudado a mejorar el bienestar de las familias de estas trabajadoras y a proporcionar un flujo constante de remesas para sus países de origen (Legco, 2017). Sin embargo, dicho esquema de trabajo se ha prestado para que se den casos de explotación laboral, o, en el peor de los casos, un aumento significativo en el tráfico de mujeres mediante agencias de empleo.

Hong Kong es destino, lugar de tránsito y, en menor medida, territorio de origen para hombres, mujeres y niños sometidos a trabajos forzados y al tráfico sexual. Las víctimas incluyen ciudadanos de China continental, Indonesia, Filipinas, Tailandia y otros países del sudeste asiático, así como de países del sur de Asia, África y Sudamérica. La trata de personas, el trabajo forzado, la explotación laboral, e incluso la esclavitud, son problemas cada vez más graves en Hong Kong. A pesar de los llamamientos por parte de académicos, sociedad civil y observadores internaciones, el gobierno de la isla continúa desestimando la magnitud del problema.

Por tercer año consecutivo, Hong Kong fue incluido en el nivel 2 de la lista de observación contenida en el Informe de Trata de Personas publicado en junio de 2018 por el gobierno de Estados Unidos; esto posiciona a Hong Kong junto a Bangladesh, Iraq, Mali, Sudán y Zimbabue. De acuerdo con el documento, aunque el gobierno está dando pasos en la dirección correcta, la ciudad no cumple cabalmente con los estándares mínimos para la eliminación del tráfico humano (Lum, 2018). El informe criticó además la pasividad de las autoridades, ya que al final sólo se identificaron nueve víctimas en 2017, luego de que las autoridades examinaran miles de casos potenciales. Gran parte del problema radica en que las leyes locales establecen una definición estricta de trata de personas que sólo incluye casos 
con fines de prostitución, además de que no existen datos oficiales del gobierno sobre las víctimas.

Los principales esfuerzos para combatir la trata de personas y la explotación laboral provienen de organizaciones no gubernamentales (ONG) subsidiadas por empresas o por ciudadanos. Específicamente, hay al menos 20 organizaciones benéficas registradas en la ciudad cuyo objetivo principal es apoyar a las trabajadoras domésticas que sufrieron abusos, o bien a víctimas de tráfico humano en Hong Kong. El equipo de trabajo de la ONG AntiTráfico de Personas, compuesto por 27 grupos de la sociedad civil, logró identificar a 63 víctimas de los 1037 presuntos casos de trata de personas que recibieron entre agosto de 2017 y junio de 2018. De los 63 casos, 59 involucraron explotación laboral, dos víctimas fueron forzadas a la prostitución, un caso fue un matrimonio forzado y otro involucró explotación sexual y laboral. $70 \%$ de las víctimas tenían visas de trabajadoras domésticas. Indonesia e India tuvieron el mayor número de víctimas, 24 y 18, respectivamente (Lum, 2018). Sin duda estos 63 casos representan sólo una muestra del gran problema de tráfico de personas y de explotación laboral que existe en la ciudad.

\section{EL TIFÓN MANGKHU Y SUS SECUELAS}

El tifón Mangkhut, que ha sido la tormenta más intensa del planeta en lo que va del año, golpeó a Hong Kong el 16 de septiembre y causó daños significativos. La tormenta azotó primero el norte de Filipinas cuando era categoría cinco. Aunque se debilitó ligeramente al cruzar el mar del sur de China; el Observatorio de Hong Kong emitió señal 10. El daño causado por el tifón Mangkhut en Hong Kong ha sido considerable, con más de 400 personas heridas, afortunadamente ninguna víctima fatal (Mahtani, 2018).

El mayor caos lo experimentó el sistema de transporte de la isla; la hora pico de la mañana del 17 de septiembre fue particularmente tortuosa para muchas personas. Más de mil secciones de caminos fueron bloqueadas por árboles caídos y otros escombros. Los servicios de autobús se cancelaron y el servicio de la Línea de Ferrocarril del Este fue irregular (Mahtani, 2018). Además, la tormenta dejó varados a decenas de miles de pasajeros en el Aeropuerto Internacional de Hong Kong, donde se suspendieron los viajes aéreos, lo que provocó 889 retrasos o cancelaciones. Aunque, para ser justos, el gobierno de la isla hizo un 
buen trabajo al dar las primeras advertencias y en los preparativos antes de la llegada del tifón, cuyo éxito reside en el sistema de vigilancia y monitoreo con el apoyo de la comunidad.

No obstante que la jefa del Ejecutivo Carrie Lam instó a los empleadores a ser considerados y flexibles con los trabajadores que llegaran tarde, también mencionó que era decisión de éstos decidir un arreglo laboral. Una encuesta publicada días después de que el tifón Mangkhut golpeara la ciudad, señaló que aproximadamente tres de cada diez trabajadores hongkoneses dijeron que su jefe reduciría su salario, bonificación e incluso parte de sus vacaciones si faltaban a trabajar durante o justo después que la tormenta golpeara la ciudad. Ése fue especialmente el caso de las personas que trabajan en administración, seguridad, turismo, servicio de comidas, logística y sector médico. El Departamento del Trabajo tiene un código de práctica para empleadores y empleados durante tifones y tormentas; de acuerdo con éste, ambas partes deben llegar a arreglos especiales conjuntamente, y los empleadores deben proporcionar transporte a los empleados, "si es posible" (Lo, 2018). También sugiere que los jefes "consideren" un pago extra debido a las condiciones climáticas, además de comida y agua. Sin embargo dichas acciones también dependen de la voluntad de los empleadores.

Hong Kong ha lidiado de manera efectiva con los desastres naturales debido al desarrollo de buena infraestructura, logística y efectiva comunicación con la sociedad civil. Según los registros del observatorio, los tifones más letales en la historia de la ciudad fueron Wanda en 1962, que cobró 130 vidas, y Rose en 1971, que mató a 110 personas. Desde entonces Hong Kong ha logrado sobrevivir muchas tormentas sin pérdidas humanas, lo cual se debe al arduo trabajo del gobierno hongkonés. Tales datos podrían no parecer significativos, sin embargo, cuando consideramos que el tifón Mangkhut mató a más de 100 personas en Filipinas, y que el huracán Florence causó más de 40 muertes en Estados Unidos, resulta importante analizar cómo se prepara el gobierno de Hong Kong para hacer frente a dichas eventualidades. Las medidas de concientización pública mejoraron la preparación de los ciudadanos para esta tormenta. Muchas personas acudieron a los supermercados para comprar artículos de primera necesidad desde tres días antes de Manghkut, lo que demuestra un nivel sin precedentes de sensibilidad pública.

El paso de Mangkhut destrozó cientos de ventanas, arrancó más de 17 mil árboles y bloqueó más de mil carreteras. Una vez que pasó la tormenta, miles de trabajadores y 
contratistas gubernamentales se desplegaron todos los días desde que pasó la tormenta, para limpiar los escombros y derribar árboles; pero se espera que la restauración en algunas de las áreas más afectadas tarde meses. Debido a la escala masiva de destrucción, simplemente esperar que el gobierno maneje toda la operación de limpieza hubiera sido poco realista, por lo que en muchos casos la sociedad civil también participó en los trabajos de reconstrucción.

Dado que hubo inundaciones graves en varias partes de Hong Kong, el reto ahora es cómo mejorar el sistema de drenaje en esas áreas, y si se deben introducir otras medidas de prevención tan pronto como sea posible. Es un hecho que el cambio climático va a seguir afectando las regiones costeras del sur de China, y cada vez con más fuerza. En este sentido, la cooperación intergubernamental entre funcionarios y las asociaciones público-privadas en las ciudades involucradas será un factor decisivo para proteger a la población de la región en las próximas décadas.

\section{REFERENCIAS BIBLIOGRÁFICAS}

Asia Times Staff (2018), "Massive Trial Run Ahead of HK-Zhuhai-Macau Bridge opening”, 27 de septiembre. Recuperado de: http://www.atimes.com/article/massive-trial-runahead-of-hk-zhuhai-macau-bridge-opening/

Bland, B. (2018), "Hong Kong Democracy Movement Loses Ground as China Clamps Down", Financial Times, 11 de marzo. Recuperado de: https://www.ft.com/content/1e02022e-259b-11e8-b27e-cc62a39d57a0

Bryan, B. (2018), "Trump Threatens to Double Down on his Trade War with China-And the Fight Could be About to get Ugly", Bussines Insider, 2 de agosto. Recuperado de: https://www.businessinsider.com/trump-china-trade-war-tariff-chinese-imports-2018-8

Cheng, K. (2018), “British Gov't Expresses 'Growing Concern' Over Freedom of Speech in Hong Kong", Hong Kong Free Press, 7 de septiembre. Recuperado de: https://www.hongkongfp.com/2018/09/07/british-govt-expresses-growing-concernfreedom-speech-hong-kong/

Cheung, T. (2017), "Six Things to Know about Hong Kong's Controversial 'Co-Location' Joint Checkpoint Scheme", South China Morning Post, 27 de diciembre. Recuperado 
de: https://www.scmp.com/news/hong-kong/politics/article/2125805/six-thingsknow-about-hong-kongs-controversial-co-location

Cheung, T. (2018), "Hong Kong Leader Carrie Lam Says Government Morale and Unity has Improved During her First Year in Office", South Morning China Post, 1 de julio. Recuperado de: https://www.scmp.com/news/hongkong/politics/article/2153306/hong-kong-leader-carrie-lam-says-government-moraleand-unity

Cheung, T y X. (2018), "Students who Associate with Outlawed Hong Kong National Party Can Face Criminal Sanctions, Government tells Schools as Top Beijing Official Welcomes Ban", South China Morning Post, 26 de septiembre. Recuperado de: https://www.scmp.com/news/hong-kong/politics/article/2165839/national-party-banessential-and-legally-sound-says-chinas

Davis, M. (2018), China's Hard Line on Hong Kong Only Undermines Confidence in the City. So Why Do It?", South China Morning Post, 16 de agosto. Recuperado de: https://www.scmp.com/comment/insight-opinion/hong-kong/article/2159816/chinashard-line-hong-kong-only-undermines

Englund, J. (2018), “China's Hardened Stance on Hong Kong and Taiwan”, The Diplomat, 4 de abril. Recuperado de: https://thediplomat.com/2018/04/chinas-hardened-stanceon-hong-kong-and-taiwan/

GovHK (2018), Hong Kong's Gini Coefficient Compared with Other Economies. Recuperado de: https://www.hkeconomy.gov.hk/en/pdf/gini_comparison.pdf

GovHK (2018), Hong Kong Economy. Recuperado de: https://www.hkeconomy.gov.hk/en/home/index.htm

Haas, B. (2017), "Hong Kong's Poor Live in Homes Smaller than Prison Cells: Study", The Guardian, 1 de noviembre. Recuperado de: https://www.theguardian.com/world/2017/nov/01/hong-kongs-poor-live-in-homessmaller-than-prison-cells-study

Haas, B. (2018), "Enemy of the State? Agnes Chow, The 21-Year-Old Activist who Has China Worried", The Guardian, 4 de febrero. Recuperado de: 
https://www.theguardian.com/world/2018/feb/04/agnes-chow-hong-kong-activistwho-has-china-worried-democracy

Haas, B. (2018a), "Hong Kong Elections Results: Blow for Pro-Democracy Movement with Lost Seats", The Guardian, 12 de marzo. Recuperado de: https://www.theguardian.com/world/2018/mar/12/hong-kong-elections-results-blowfor-pro-democracy-movement-with-lost-seats

Haas, B. (2018b), "Hong Kong Cedes Part of Rail Station to China in Secretive Ceremony", The Guardian, 4 de septiembre. Recuperado de: https://www.theguardian.com/world/2018/sep/04/hong-kong-cedes-part-of-westkowloon-rail-station-to-china-in-secretive-ceremony

Hale, E. (2018), “An Impressive, Unnecessary, Multi-City Bridge”, Citylab, 15 de agosto. Recuperado de: https://www.citylab.com/transportation/2018/08/an-impressiveunnecessary-multi-city-bridge/567284/

Huang, C. (2018), "Hong Kong Chief Carrie Lam Gives Upbeat Assessment of 1st Year in Office", The Strait Times, 2 de julio. Recuperado de: https://www.straitstimes.com/asia/carrie-lam-gives-upbeat-assessment-of-1st-year-inoffice

HZM (2018) Hong Kong-Macau-Zhuhai Bridge, 20 de septiembre. Recuperado de: http://www.hzmb.org/en/list.asp?id=1

Kihara, T y M. Chan (2018), "Hong Kong's Worsening Housing Shortage Forces Thousands Into 'Coffin Homes", Asia Nikkei, 9 de julio. Recuperado de: https://asia.nikkei.com/Economy/Hong-Kong-s-worsening-housing-shortage-forcesthousands-into-coffin-homes2

Kuo, L. (2018), "Hong Kong Bans Pro-Independence Party as China Tighten Grip", The Guardian, 24 de septiembre. Recuperado de: https://www.theguardian.com/world/2018/sep/24/hong-kong-bans-pro-independenceparty-as-china-tightens-grip

Legco (2017), "Foreign Domestic Helpers and Evolving Care Duties in Hong Kong", Research Office Legislative Council Secretariat. Recuperado de: 
https://www.legco.gov.hk/research-publications/english/1617rb04-foreign-domestichelpers-and-evolving-care-duties-in-hong-kong-20170720-e.pdf [Research Brief Issue No. 42016 - 2017].

Lo, S. (2018), "What Typhoon Mangkhut Taught Us: The Value of Being Prepared and Regional Cooperation", South China Morning Post, 17 de septiembre. Recuperado de: https://www.scmp.com/comment/insight-opinion/hong-kong/article/2164541/whattyphoon-mangkhut-taught-us-value-being

Lum, A. (2018), "Hong Kong Group Identifies More Than 60 Human Trafficking Cases in City over Past Year", South China Morning Post, 31 de julio. Recuperado de: https://www.scmp.com/news/hong-kong/hong-kong-law-andcrime/article/2157528/hong-kong-group-identifies-more-60-human

Mahtani, S. (2018), “Typhoon Mangkhut Battered Hong Kong's Storied History”, The Washington Post, 17 de septiembre. Recuperado de: https://www.washingtonpost.com/world/2018/09/17/typhoon-mangkhut-batteredhong-kongs-storied-history/?utm_term $=.843$ e509f9633

Moon, L. (2018), “Hong Kong, World's Most Overvalued Housing Market, is at Greatest Risk of Bubble, Says UBS", South China Morning Post, 28 de septiembre. Recuperado de: https://www.scmp.com/property/international/article/2166080/hong-kong-worldsmost-overvalued-housing-market-greatest-risk

Ramzey, A. (2018), "Hong Kong Bans Pro-Independence Party", New York Times, 24 de septiembre. Recuperado de: https://www.nytimes.com/2018/09/24/world/asia/hongkong-party-ban-andy-chan.html

Rios, X. (2018), "Xi de por vida", El Pais, 26 de febrero. Recuperado de: https://elpais.com/internacional/2018/02/26/actualidad/1519649146_158906.html

SCMP Staff. (2017), "Full Text of President Xi Jinping's Speech on 'One Country, Two Systems' and How China Rules Hong Kong”, South Morning China Post, 1 de julio. Recuperado de: https://www.scmp.com/news/hong-kong/politics/article/2100856/fulltext-president-xi-jinpings-speech-one-country-two 
Shane, D. (2018), "Hong Kong Now has More Super-Rich People than Any Other City", CNN Money, 6 de septiembre. Recuperado de: https://money.cnn.com/2018/09/06/investing/world-richestpeople'cities/index.html?utm_source=fbmoney\&utm_content=2018-0906T11\%3A00\%3A09\&utm_term=link\&utm_medium=social

Tsang, D. (2018), “How Will Hong Kong be Affected by the US-China Trade War?”, South Morning China Post, 2 de agosto. Recuperado de: https://www.scmp.com/news/hongkong/hong-kong-economy/article/2155301/how-will-hong-kong-be-affected-uschina-trade-war

Tweed, D. (2018), "New Hong Kong Housing Policies Will Bring Focus, Carrie Lam Says", Bloomberg, 30 de junio. Recuperado de: https://www.bloomberg.com/news/articles/2018-07-01/new-hong-kong-housingpolicies-will-bring-focus-carrie-lam-says

Wong, M. (2017), “Comparative Hong Kong Politics. A Guide for Students and Researches", Palgrave Macmillan, University of Hong Kong, pp.300

Zweig, D. (2017), “The Future of Democracy in Hong Kong: A Conversation with David Zweig", CSIS. Recuperado de: https://soundcloud.com/csis-57169780/the-future-ofdemocracy-in-hong-kong-a-conversation-with-david-zweig 